\title{
A utilização de recursos educacionais digitais no ambiente escolar: da formação continuada à vivência tecnológica
}

\author{
Rayssa Araújo Hitzschky', Cintia Arruda Lima², Juliana Silva Arruda1, \\ Danilo do Carmo de Souza ${ }^{1}$, Liliane Maria Ramalho Siqueira ${ }^{1}$, José Aires de \\ Castro Filho ${ }^{2}$ \\ 1 Programa de Pós-Graduação em Educação - UFC. \\ 2 Universidade Federal do Ceará - UFC. \\ \{hitzschkyrayssa, arrucintia, julianarruda24, danilocarmo1992, \\ lilianeramalho1609\} @gmail.com, aires@virtual.ufc.br
}

\begin{abstract}
This study seeks to investigate the contributions of a teacher training aimed at the appropriation of digital educational resources (RED) in teaching practice. The research, with a qualitative approach, had as participants a group of teachers of Portuguese Language and Mathematics of the final years of Elementary School, from a public school in Ceará. The results point to the importance of the diagnosis on the use of ICT, as a way of delineating, in a more contextualized way, the moments of study of a teacher formation. In addition, the relationship between theory and practice has proved to be a significant element for teachers, given that the knowledge they achieve needs meaning in their lived practice.
\end{abstract}

Resumo. Este estudo busca investigar as contribuições de uma formação de professores voltada para a apropriação de recursos educacionais digitais (RED) na prática docente. A pesquisa, de abordagem qualitativa, teve como participantes um grupo de professores de Língua Portuguesa e de Matemática dos anos finais do Ensino Fundamental, de uma escola pública cearense. Os resultados apontam a importância do diagnóstico sobre o emprego das TIC, como forma de delinear, de maneira mais contextualizada, os momentos de estudo de uma formação docente. Além disso, a relação entre teoria e prática mostrou-se como um elemento significativo para os docentes, tendo em vista que os saberes alcançados necessitam de sentido em sua prática vivida.

\section{Introdução}

As transformações vivenciadas pela sociedade contemporânea revelam nuances que afetam aspectos sociais, culturais, econômicos e educacionais. As distintas facetas trazidas pelas Tecnologias da Informação e Comunicação (TIC) repercutem em sala de aula e na ação pedagógica, por meio da introdução de novas ferramentas digitais que possibilitam dinâmicas metodológicas antes desconsideradas.

Frente ao expressivo quantitativo de recursos digitais disponíveis na web, docentes deparam-se com dificuldades no acesso e no planejamento destes materiais para posterior utilização na sua própria organização de ensino. Esse movimento dialógico os desloca na busca por ferramentas que promovam a melhoria do processo educacional, surgindo possibilidades a partir do uso de ferramentas on-line colaborativas, blogs, vídeos e 
VII Congresso Brasileiro de Informática na Educação (CBIE 2018)

Anais do XXIV Workshop de Informática na Escola (WIE 2018)

mecanismos de edição. As perspectivas educacionais percebidas para esses recursos enriquecem sua aplicação. No presente trabalho, denomina-se estes de recursos educacionais digitais (RED).

No entanto, a formação oferecida ao educador possui fragilidades em relação ao uso das TIC como instrumento de sua prática pedagógica. Podem ser exemplificadas o "desconhecimento dos professores em relação às TIC, a natureza tecnicista e superficial dos cursos de formação, a relação de sentido atribuída pelos professores e a integralização curricular deficitária dos cursos de licenciatura das Instituições de Ensino Superior." [BONILLA, p. 73, 2012]

Diante das lacunas formativas apresentadas pelos educadores em relação às tecnologias digitais, originou-se a seguinte questão: de que maneira a oferta de uma formação de professores que trata do aprofundamento sobre os RED impacta a prática docente? Desse modo, têm-se como objetivo geral: averiguar a influência de uma formação de professores voltada para o trabalho com diferentes recursos educacionais digitais na prática pedagógica. Como objetivos específicos: 1) analisar o uso pedagógico das tecnologias digitais pelos professores; 2) investigar as possibilidades de uma formação docente baseada na relação entre teoria e prática para uso de recursos educacionais digitais.

O estudo busca contribuir para a formação de professores no tocante ao uso de RED, a fim de colaborar para o aprimoramento da atuação docente, ao envolver teoria e prática nas vivências pedagógicas. Segue-se o referencial teórico, os procedimentos metodológicos, a análise e discussão dos achados e, por fim, as considerações finais.

\section{Integração das tecnologias digitais à formação docente: possibilidades para a prática pedagógica}

As tecnologias digitais impulsionam reformulações para a estruturação educacional, revelando uma "tendência de intelectualização do processo de produção, implicando mais conhecimento, uso da informática e de outros meios de comunicação, habilidades cognitivas e comunicativas, flexibilidade de raciocínio, etc." [LIBÂNEO, p. 14, 1998]

Oliveira [2017] argumenta que a inserção das tecnologias digitais na educação possibilitou a obtenção de projetores, lousas digitais e a implantação de laboratórios de informática, relacionando, cada vez mais, a tecnologia aos processos de ensino e de aprendizagem. Nos dias atuais, percebe-se que os professores tem uma gama de recursos tecnológicos ao seu alcance, os quais podem fomentar ambientes mais participativos e hipermidiáticos.

Contudo, segundo Veiga [1992], até 1930, os cursos de formação docente eram caracterizados pelo dogmatismo de conteúdos, utilização de metodologias universais e verticalização. A formação docente perpassava a separação entre teoria e prática, além da inexistência de artefatos tecnológicos, tais como desktops, laptops ou smartphones. Em sua formação inicial, os professores eram preparados para uma realidade escolar unicamente analógica.

Posteriormente, com tendências mais progressivas, a escola mudou juntamente com a sociedade, a estrutura das salas e os alunos são outros, mas os professores permanecem os mesmos. A formação inicial docente não abrange saberes voltados para o uso das tecnologias digitais em sala de aula, demonstrando que "os objetivos educacionais propostos nos currículos dos cursos apresentam-se confusos e desvinculados da realidade social." [VEIGA, p. 41, 1992b]. Com isso, os professores 
VII Congresso Brasileiro de Informática na Educação (CBIE 2018)

Anais do XXIV Workshop de Informática na Escola (WIE 2018)

atuantes nos ambientes formais e não formais de ensino encontram-se distantes das novas mudanças que ressignificam o ambiente escolar.

Nesse contexto, diversos documentos oficiais revelam preocupação com a inserção das TIC no ensino e na aprendizagem. Segundo Chauí [2001], a Lei de Diretrizes e Bases da Educação (LDB) destaca a relação entre a mão de obra humana e as constantes transformações nas atividades curriculares, com $\mathrm{o}$ intuito de atender às novas metodologias. De forma particular, mais recentemente, a Base Nacional Comum Curricular (BNCC) afirma que os alunos devem "compreender, utilizar e criar tecnologias digitais de informação e comunicação de forma crítica, significativa, reflexiva e ética nas diversas práticas sociais para se comunicar, acessar e disseminar informações, resolver problemas e exercer protagonismo e autoria." [BRASIL, p. 9, 2017]. Esse trecho enfatiza que a organização escolar deve considerar a influência da cultura digital em seus processos, oferecendo múltiplos ambientes de aprendizagem inseridos em uma conjuntura social mais ampla, diversificada e multiletrada.

David e Castro-Filho [2012] descrevem as oportunidades de aprendizagem que as ferramentas tecnológicas têm provocado ao longo dos processos de aquisição do conhecimento. Diversos recursos digitais adquirem contornos educativos, buscando o aperfeiçoamento dos processos, dentre eles, ferramentas não pensadas com fins educacionais, como Google Drive e WhatsApp. Para essa articulação, Veiga [1996] argumenta que a formação docente deve oportunizar uma unidade ao processo educacional, proporcionando aos alunos o aprender ativo curricular e atendendo às exigências da vida em sociedade.

Constitui-se papel da escola e, particularmente do professor, mediador da formação discente, estabelecer relações de sentido entre os saberes da cultura escolar àqueles referentes à digital, em práticas situadas de conhecimento. Para tanto, se o docente não tem proximidade com as TIC em contextos formais de ensino, a formação continuada é um possível caminho para o sucesso dos seus afazeres pedagógicos [NÓVOA, 1995].

O saber docente, portanto, não deve ser visto como definitivo, e sim articulado à sua prática, à sua experiência de vida e às formações profissionais. Inclui-se, assim, a correspondência imbricada entre a didática e a formação docente, visto que Passos [2006] considera que a didática deve favorecer a formação docente, através de um contexto político, cultural, ético e psicológico, pautada numa prática envolvida em um meio social mais complexo.

Para situar os alunos ao contexto social emergente, em especial, ao emprego das TIC, o professor deve entender as mudanças, estabelecendo vínculos entre as ações pedagógicas, a realidade e os anseios dos aprendentes. Nesse âmbito, projetos com vínculo às universidades promovem o fomento de ações que visam a formação continuada docente para uso das tecnologias digitais.

Os estudos de Silva e Castro-Filho [2015] e Silva [2014] demonstram o desenvolvimento profissional docente por meio da vivência em sala de aula com uso das TIC e a produção de planejamentos e projetos colaborativos em rede com uso do computador. Essas experiências demonstram as contribuições oferecidas pelo repertório do saber da academia e o aplicado na vivência escolar, percebendo-se uma ressignificação da prática pedagógica em vias de concretude. O ambiente educacional, espaço de aprendizagem contínua e onde as tecnologias digitais estão gradativamente mais presentes, vem fornecendo novos contextos de atuação docente. 
VII Congresso Brasileiro de Informática na Educação (CBIE 2018)

Anais do XXIV Workshop de Informática na Escola (WIE 2018)

A formação dos educadores deve estar relacionada às demandas sociais para a constituição de saberes correlacionados, com direções que buscam a concretização plena da aprendizagem, sendo repleta de subjetividades e narrativas de vida. Dessa forma, a interação entre tecnologias digitais, professores e alunos é favorecida, a fim de suscitar reflexões individuais e coletivas. Em seguida, serão descritos os procedimentos metodológicos do estudo.

\section{Procedimentos metodológicos}

O estudo foi desenvolvido no contexto de implementação de um laboratório de inovação tecnológica da Google, instalado em uma escola da rede pública de Fortaleza, Ceará, por meio da parceria entre a Enel, Multilaser e a Universidade Federal do Ceará (UFC). Tevese como objetivo o fomento e a disponibilização de diferentes ferramentas digitais para a comunidade escolar, proporcionando, desse modo, novas dinâmicas aos processos educacionais de professores e alunos.

Entende-se que não é necessária, somente, a disposição isolada das tecnologias digitais na escola. Por isso, foram realizadas intervenções, dentre elas um curso de formação de professores, entre os meses de maio a novembro de 2017. Com essa ação, buscou-se a vivência pedagógica com RED pelos docentes, a partir da promoção de práticas colaborativas com emprego das TIC. A amostra abrangeu educadores de Língua Portuguesa e de Matemática dos anos finais do Ensino Fundamental, com formações realizadas na própria escola. Participaram da formação sete professores, incluindo quatro de Língua Portuguesa e três de Matemática.

A partir da inserção do laboratório, iniciou-se o processo de formação docente para uso dos RED. Perpassou-se quatro fases de investigação: 1) averiguação do uso pedagógico das TIC pelos docentes; 2) estudo de aspectos teóricos sobre os RED e suas aplicações; 3) articulação da teoria às situações práticas de inserção dos RED nos processos educacionais; 4) transposição dos saberes adquiridos durante a formação, a partir da elaboração de planejamentos com uso de RED que, posteriormente, foram trabalhados em sala.

As tecnologias digitais utilizadas pelos professores na formação incluíram laptops, chromebooks (notebook com funcionalidades off-line), e projetor; animações e vídeos presentes no repositório Athena, desenvolvido pela equipe de formação, além de ferramentas colaborativas do Google Drive e Google Classroom. Ainda, o WhatsApp foi adotado como um canal de comunicação entre os pesquisadores e os docentes.

A metodologia do estudo é de natureza qualitativa, realizada a partir da análise das situações formativas, da postura e das estratégias utilizadas pelos docentes ao longo do curso de formação. $\mathrm{Na}$ abordagem qualitativa tem-se como principal objetivo a estruturação do conhecimento e não somente a catalogação de resultados [BOGDAN; BIKLEN, 1994].

Como técnicas de análise, utilizou-se a observação participante, tendo em vista que o pesquisador participa ativamente das atividades em conjunto com o observado [LAKATOS; MARCONI, 2003] e a triangulação metodológica, para conhecimento do perfil docente e das contribuições oferecidas pela formação. Para esse fim, foram utilizados diários de campo, depoimentos, produções coletivas e interações, fotos e áudios, bem como questionários iniciais, parciais e finais do Google Drive aplicados junto ao público participante. Na próxima seção, serão apresentados os resultados e as discussões coletadas durante a formação. 
VII Congresso Brasileiro de Informática na Educação (CBIE 2018)

Anais do XXIV Workshop de Informática na Escola (WIE 2018)

\section{Resultados e discussões}

Os resultados deste estudo têm por base o desenvolvimento da formação docente, partindo da relação entre os aportes teóricos e práticos da vivência tecnológica experienciada. Nesse sentido, importa considerar que os dados não se encontram isolados. Logo, são explorados trechos dos diários de campo e dos questionários concernentes às quatro fases dos encontros, que analisam as contribuições dos RED para a formação continuada docente.

\subsection{Primeira fase}

Os momentos da formação foram iniciados pela avaliação diagnóstica do grupo, por meio de um formulário on-line de análise do uso pedagógico das tecnologias digitais pelos docentes. Essa sondagem é um importante momento para o início da formação, tendo em vista que a aproximação com o público participante é crucial para a tomada de decisão das ações.

Diante das respostas presentes no questionário e de conversas informais, os professores afirmaram que já utilizavam as TIC em suas experiências escolares. Segundo levantamento das respostas, a Internet e o projetor multimídia foram considerados os recursos tecnológicos mais utilizados (100\%); seguidos do notebook e dos RED (44,4\%); laptop educacional $(33,3 \%)$; desktops, tablets e smartphones $(11,1 \%)$. Entretanto, essa fala foi desmitificada à medida que a aproximação dos pesquisadores era estabelecida com o grupo docente. Observou-se que esse discurso se baseou no uso das TIC de maneira tecnicista, revelando a exposição tradicional e vertical da fala docente por meio do uso frequente de slides, como explana Veiga [1992].

A partir da vivência tecnológica-educacional docente, foi desenvolvido um cronograma de ações voltado para as lacunas formativas apresentadas pelos professores em relação às tecnologias digitais. No formulário de avaliação inicial, abriu-se um espaço para sugestão de ferramentas digitais para estudo e foram destacadas: Google Drive, jogos educativos, ferramentas para construção de gráficos e RED. Com isso, foram traçadas ações de acordo com as necessidades e as próprias demandas dos docentes, contemplando o processo participativo e colaborativo de aprendizagem.

\subsection{Segunda fase}

A formação possibilitou que os professores percebessem novos usos, antes despercebidos, das tecnologias digitais em sala de aula para além do uso de slides. Entretanto, essa reflexão causou desconfiança em relação aos novos conhecimentos trabalhados, essencialmente, nos momentos de trabalho colaborativo com as ferramentas do Google Drive, por meio do Google Classroom, e para a realização das atividades práticas.

Diante dos registros dos diários de campo e depoimentos dos participantes, verificou-se uma resistência para as possibilidades formativas oferecidas, que foi sanada com a própria percepção de sentido empreendida pelos professores acerca das contribuições das TIC às suas práxis. A aproximação estabelecida pelos docentes foi percebida por meio de questionamentos, feitos durante os encontros e no grupo do WhatsApp, bem como pedidos de sugestão e de auxílio com as ferramentas digitais.

Nesse momento, apresentou-se aos professores referenciais teóricos relacionados aos recursos educacionais e às tecnologias digitais em geral. Foram trabalhados os seguintes conceitos: 1) repertório das TIC, incluindo, repositórios educacionais, objetos 
de aprendizagem (OA), RED e ferramentas colaborativas; 2) conceituação de OA e de recursos educacionais digitais; 3) tipos de RED, como vídeos, hipertextos, softwares e animações; 4) critérios de seleção de RED, à luz de Oliveira et al [2001]; 5) definição de RED, segundo Afonso et al [2011], e respectivos exemplos, com ênfase no repositório Athena; 6) definição de metadados e estudo das licenças de uso; 7) descritores da matriz de referência do Sistema de Avaliação da Educação Básica (SAEB), tendo em vista que esse documento é largamente utilizado pelos professores da rede pública em seus planejamentos e avaliações; 8) estudo de planejamentos com utilização de RED; 9) ferramentas colaborativas do Google Drive e Google Classroom.

No formulário on-line de avaliação parcial (Gráfico 1), 87,5\% dos professores considerou que a abordagem teórica sobre definição de RED e OA, tipos de RED e repositórios educacionais digitais foram os conteúdos mais significativos para a sua práxis; $75 \%$ ponderou que a apresentação e o trabalho com o repositório Athena foi a teoria mais relevante durante os encontros; $37,5 \%$ afirmou que o estudo de critérios para seleção de RED foi o momento teórico mais considerável; $12,5 \%$ englobou o modelo de planejamento com uso de RED como situação teórica mais pertinente; e 12,5\% considerou como abordagem teórica de destaque os metadados, direitos autorais e licenças de uso. Tomou-se como ponto de partida o arcabouço teórico em cinco vertentes maiores, buscando otimizar o instrumento de avaliação.

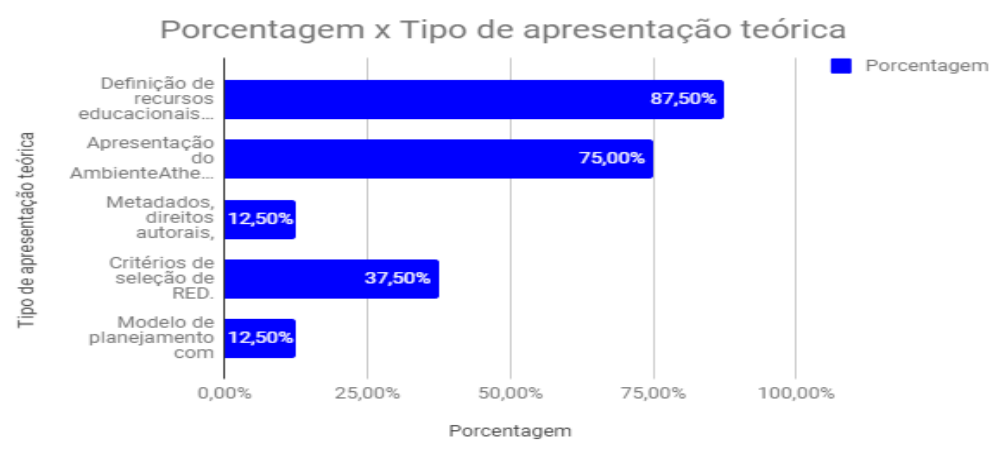

Gráfico 1. Avaliação dos momentos teóricos

Percebe-se, assim, que o arcabouço teórico mais expressivo para os docentes foram aqueles relacionados à sua prática, de modo que esses conteúdos poderiam contribuir com os seus planejamentos pedagógicos e com o dia a dia de suas aulas.

\subsection{Terceira fase}

Após algumas apresentações teóricas, foi realizado um trabalho simultâneo entre teoria e prática. Verificou-se, nesses encontros, que a participação dos professores era mais qualitativa com a proposição dessa dinâmica, no sentido de que o envolvimento se mostrou mais elevado e recorrente com a adoção dessa organização. Assim, à medida que as apresentações teóricas eram feitas, ao final de cada encontro, os professores desenvolviam trabalhos práticos.

Como momentos teóricos e práticos simultâneos, transcorreram-se: 1) pesquisa inicial e individual de um RED; 2) análise individual de um RED e seus descritores; 3) análise conjunta, incluindo, formadores e docentes, de recursos educacionais presentes no repositório Athena; 4) análise colaborativa de um RED com uso do Google Drive. 
VII Congresso Brasileiro de Informática na Educação (CBIE 2018)

Anais do XXIV Workshop de Informática na Escola (WIE 2018)

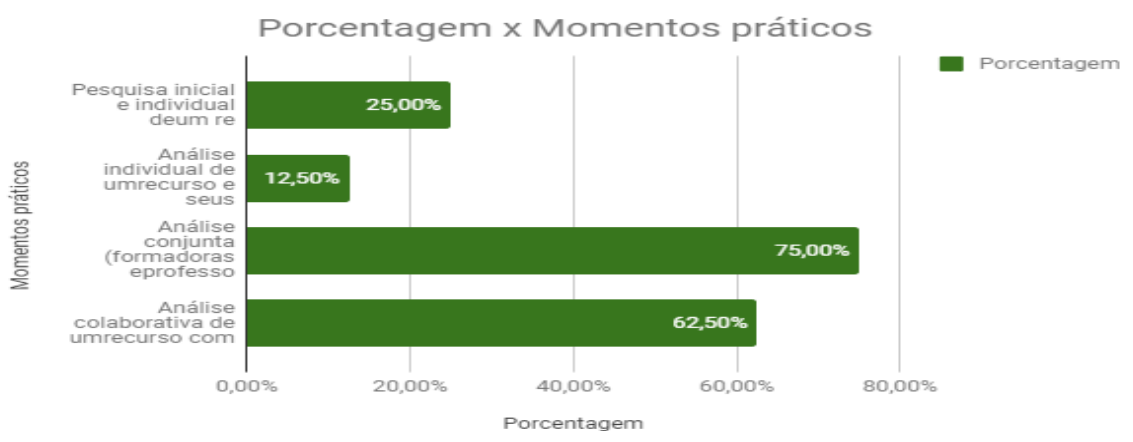

Gráfico 2. Avaliação dos momentos práticos

O formulário de análise parcial (Gráfico 2) demonstrou que para 75\% dos docentes, a análise conjunta, entre formadores e professores, de RED presentes no repositório Athena foi considerado o momento teórico e prático mais relevante. Em seguida, para $62,5 \%$ dos docentes, a análise colaborativa de um RED com uso do Google Drive foi classificada como um dos momentos mais significativos. Após, seguiu-se a pesquisa inicial e individual de um recurso, com $25 \%$ e, por último, a análise individual de um recurso e seus descritores, com $12,5 \%$.

Infere-se, dessas informações, que o trabalho colaborativo em uma formação enriquece as vivências pedagógicas para o uso de RED, considerando que estas podem se inter-relacionar e se complementar como corrobora Franco [2005], em uma ação-reflexão coletiva.

\subsection{Quarta fase}

A última etapa caracterizou-se por práticas pedagógicas com uso de RED. Após o estudo dos conhecimentos teóricos e dos momentos práticos nos quais os docentes relacionaram a teoria com a prática situada, estes produziram planejamentos pedagógicos com utilização de recursos educacionais digitais para aplicação em sala de aula.

Para tanto, a equipe de formação desenvolveu, de forma conjunta com os professores, um cronograma de aplicação dos planejamentos, demonstrando a necessidade da formação ser um processo participativo, autoral e colaborativo entre formador e professor. Desse modo, os docentes escolheram as datas de aplicação e todas as aulas, ao todo sete, foram acompanhadas pela equipe de formação, com o intuito de auxiliar os professores e não de avaliá-los.

Para os seus planejamentos, eles realizaram buscas no repositório Athena, de acordo com critérios estudados nas etapas anteriores, objetivando a seleção de um RED para compor os seus planos de aula. Esse movimento revela situações teóricas e práticas que envolvem o gerenciamento e a reelaboração de si enquanto sujeito aprendente. Como ratifica Passos [2006], a formação do professor deve perpassar uma didática que trabalhe com uma visão de ensino contextualizada, imersa em uma prática social mais ampla.

Detalhado em diário de campo, verificou-se que, no decorrer das aulas, os professores demonstraram uma boa justaposição entre teoria e prática com uso dos recursos educacionais digitais, relacionando os conhecimentos de seleção dos RED em seus planejamentos, assim como pela análise e transposição das possibilidades dos recursos para as aulas. Porém, em momentos pontuais, os professores apresentaram 
VII Congresso Brasileiro de Informática na Educação (CBIE 2018)

Anais do XXIV Workshop de Informática na Escola (WIE 2018)

dificuldades com o uso dos laptops e dos chromebooks, que foram sanadas com o auxílio da equipe de formação.

Os docentes usaram animações e vídeos para o ensino dos seguintes conteúdos: em Língua Portuguesa, conjunções, pontuação, morfossintaxe e relações de sentido e em Matemática, as quatro operações com números inteiros, equações de $1^{\circ}$ grau e frações equivalentes. A mediação docente foi um aspecto imprescindível durante as aulas, posto que eles exploraram os recursos junto com os alunos e intercalaram-na com outras estratégias, como o acesso em sites de busca. Ainda, notou-se que os professores, primeiramente, apresentavam o conteúdo e, em seguida, trabalhavam com os recursos educacionais, como forma de complemento à exposição anterior. Os alunos eram dispostos em duplas ou trios nos laptops e o professor observava a realização da atividade e auxiliava-os em situações de dúvidas. Nesse sentido, entende-se que os RED se constituem ferramentas que potencializam a aprendizagem, mas que não substituem a presença do professor como facilitador do conhecimento.

Posteriormente às aulas, a equipe de formação reuniu-se com o grupo de professores para avaliação dos momentos práticos, por meio de um formulário final e da auto avaliação, realizada presencialmente no último encontro e detalhada em diário de campo. Os docentes consideraram as aulas com utilização dos RED dinâmicas e produtivas, enfatizando a quebra da rotina. Para os professores, a formação oferecida apresentou ferramentas, ainda inexploradas por eles, e que agregaram contribuições às suas práticas.

Além disso, os docentes apontaram como ponto significativo da formação, a aproximação estabelecida pelos formadores, a qual trouxe segurança e desmistificou a desconfiança inicial apresentada pelos participantes. Outro ponto importante foram os resultados das atividades desenvolvidas pelos docentes no transcorrer da formação, como a estruturação de um planejamento com uso de RED de forma colaborativa, rompendo o distanciamento e auxiliando a construção de novos saberes.

Os saberes construídos ao longo da formação envolveram a relação entre teoria e prática aplicada em sala de aula pelos professores, a escolha autônoma e crítica dos RED que compuseram os seus planejamentos, bem como a reflexão suscitada na prática cotidiana. A fala do professor Edson (nome fictício para preservar a sua identidade) ressalta as contribuições da formação para a sua vivência pedagógica:

\begin{abstract}
Os professores até planejam uma aula diferente, mas existe uma dificuldade expressiva em relação às tecnologias, ao retroprojetor. Mesmo me intitulando um professor tradicional, com o cansaço de uma aula expositiva, cansando os alunos e a mim, a aula com uso do recurso presente no repositório Athena foi muito boa e produtiva. O uso do recurso quebrou a rotina e gerou aprendizagem, sendo refletida nas perguntas sobre quando eles iriam ter uma aula igual novamente. Os encontros da formação ajudaram a aliar teoria e aplicação prática.
\end{abstract}

Apesar das contribuições dos RED em práticas pedagógicas, os professores elencaram desafios enfrentados por eles em sua vivência com o uso das tecnologias digitais, entre eles: a deficiência estrutural das salas de aula, com falta de materiais e de recursos em geral; dificuldades na busca e na seleção de RED, pois quando os recursos são encontrados, há pouca diversidade de RED voltados para os anos finais do Ensino Fundamental.

Esses aspectos, que devem ser considerados em situações com uso das tecnologias digitais, indicam que as formações devem possuir uma base harmônica, equilibrando o vasto conhecimento teórico e a aplicação deste em ocasiões oportunas de vivência. A 
VII Congresso Brasileiro de Informática na Educação (CBIE 2018)

Anais do XXIV Workshop de Informática na Escola (WIE 2018)

maior abrangência de recursos voltados para os anos finais do Ensino Fundamental é necessária, tendo em vista que, diante de criteriosas categorizações anteriores à formação, constatou-se que os existentes são pouco diversos na abordagem de conteúdos amplamente estudados nestes anos.

\section{Considerações finais}

Ponderando sobre os caminhos da pesquisa, a amostra e os instrumentos utilizados, compreende-se que esta investigação, cujo objetivo foi o de averiguar a influência de uma formação de professores voltada para o trabalho com diferentes recursos educacionais digitais na prática docente, contribuiu para o aprofundamento do estado da arte em torno da formação de professores.

O estudo demonstrou a importância do diagnóstico sobre o emprego das tecnologias digitais, como forma de delinear, de forma mais contextualizada, os momentos de estudo de uma formação continuada de professores. Além disso, a relação entre teoria e prática mostra-se como um elemento significativo para os docentes, tendo em vista que os saberes alcançados necessitam de sentido em sua prática cotidiana.

As vivências práticas da pesquisa demonstraram que o conhecimento se encontra em constante movimento de reconfiguração, com base nas demandas sociais de cada época. Desse modo, é oportuno ressaltar que, aliado à exposição e ao levantamento dos novos saberes, os pesquisadores estiveram presentes em todo o processo, imersos no contexto educacional dos participantes e vivenciando as situações e atividades propostas. Essa postura colaborativa corrobora com o pensamento de que o estabelecimento de uma formação docente deve constituir-se um processo composto de subjetividades, mas, sobremaneira, do saber coletivo.

Percebe-se a relevância dos momentos de aproximação e ambientação vivenciados pelos docentes nas situações de aplicação dos RED. Nesse sentido, considera-se que a literatura em questão não se encontra acabada e espera-se que esse estudo possa despertar novos questionamentos. Como estudos futuros, tem-se a ampliação da pesquisa para os anos iniciais do Ensino Fundamental, buscando contemplar docentes de outras etapas de ensino.

\section{Referências}

Afonso, M. C. L.; Eirão, T. G.; Melo, J. H. M. et al. (2011). "Banco Internacional de Objetos Educacionais (BIOE): tratamento da informação em um repositório educacional digital.” Perspectivas em Ciência da Informação. v. 16, n. 3, p. 148-158, jul/set.

Bogdan, R. C; Biklen, S. K. (1994). "Investigação qualitativa em educação.” Porto, Portugal: Porto Editora.

Bonilla, M. H. S. (2012). "A presença da cultura digital no gt educação e comunicação da ANPED.” Revista Teias, v. 13, n. 30, 71-93. set./dez.

Brasil. Ministério da Educação. (2017). "Base Nacional Comum Curricular”. Brasília, DF: MEC.

Chauí, M. (2001). “Escritos sobre a universidade.” São Paulo: Unesp. CHAUÍ, Marilena. Escritos sobre a universidade. São Paulo: Unesp. 
VII Congresso Brasileiro de Informática na Educação (CBIE 2018)

Anais do XXIV Workshop de Informática na Escola (WIE 2018)

David, P. B.; Castro Filho, J. A. (2012). "Sistema de análise de interações contingentes: uma contribuição para práticas interativas em cursos a distância." Revista eCurriculum, v. 8, p. 1-28.

Franco, M. A. S. (2005). "Pedagogia da pesquisa-ação." Educação e Pesquisa. São Paulo, v. 31, n. 3, set/dez, p. 483-502.

Libâneo, J. C. (1998). "Adeus professor, Adeus professora? Novas exigências educacionais e profissão docente.” SP: Cortez.

Oliveira, C. C. O.; Costa, J. W.; Moreira, M. (2001). "Produção e avaliação de software educativo." Campinas, SP: Papirus.

Oliveira, G; Kunrath, N; Rocha, S; Silva, L. A. M. (2017). "Uso de dispositivos móveis como recurso didático na formação docente." XXVIII Simpósio Brasileiro de Informática na Educação.

Passos, C. M. B. (2006). "Didática: breve incursão histórica em busca da identidade." Fortaleza. Notas de aula.

Silva, M. A. (2014). "Trabalho colaborativo em rede no projeto Um Computador por Aluno (UCA): conhecimentos e práticas docentes.” Tese (Doutorado em Educação) Faculdade de Educação, Universidade Federal do Ceará, Fortaleza.

Silva, M. A.; Castro Filho, J. A. (2015). "Trabalho colaborativo com suporte do laptop: parceria entre professores e alunos". Workshop do IV Congresso Brasileiro de Informática na Educação. Maceió.

Veiga, I. P. A. (1992). “Repensando a didática.” Papirus: Campinas - SP.

Veiga, I. P. A (Org); Lopes, A. O.; Castanho, M. E.; Cunha, M. I.; Damis, O. T.; Rays; O. A.; Martins, O. P. L.; Castanho, S. E. M.; Kenski, V. M. (1996). "Didática: O ensino e suas relações." Papirus: Campinas - SP. 